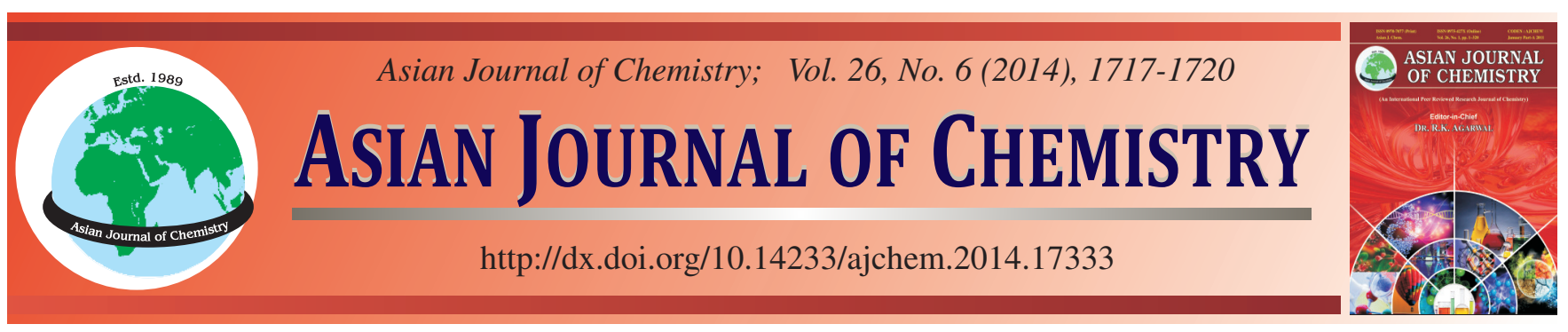

\title{
Synthesis of Furfural from D-Xylose and Corncob with Chromium Chloride as Catalyst in Biphasic System $\dagger$
}

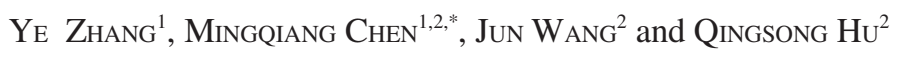

${ }^{1}$ School of Earth Science and Environmental Engineering, Anhui University of Science and Technology, Huainan 232001, P.R. China

${ }^{2}$ School of Chemical Engineering, Anhui University of Science and Technology, Huainan 232001, P.R. China

*Corresponding author: Fax: +86 554 6668742; E-mail: mqchen@ aust.edu.cn

Published online: 10 March 2014;

AJC-14875

\begin{abstract}
An efficient process was developed for the conversion of D-xylose into furfural with chromium chloride as catalyst in a biphasic system. The optimal furfural yield of $38.76 \%$ was obtained in the following reaction conditions: reaction temperature $140{ }^{\circ} \mathrm{C}$, reaction time $1 \mathrm{~h}$ and the catalyst loading $2 \mathrm{mmol}$. Sodium chloride used as co-catalyst was found to affect the furfural yield. A higher furfural yield of $52.55 \%$ was achieved in the presence of $3 \mathrm{~g}$ of sodium chloride when using chromium chloride catalyst for the dehydration of $\mathrm{D}$-xylose into furfural. The $\mathrm{CrCl}_{3} \cdot 6 \mathrm{H}_{2} \mathrm{O}-\mathrm{NaCl}$ catalytic system could be recycled and its stable activity was showed after three successive runs. Moreover, this work also provided useful information for the production of furfural from biomass. The furfural yield of $23.88 \%$ was achieved when corncob used as starting materials.
\end{abstract}

Keywords: D-Xylose, Furfural, Hydrolysis reaction, Chromium chloride, Co-catalyst, Biphasic system.

\section{INTRODUCTION}

With petroleum resources declining and environmental concerns rising, the production of energy and chemicals from renewable biomass has become an intense topic of applied and basic research. Especially, the production of furfural becomes one of the focal point of comprehensive utilization of biomass resource. Furfural, containing a furan ring and an aldehyde group, is envisaged as a potential platform chemical for the biofuels, bio-based chemicals and biopolymer industries ${ }^{1}$. Furfural is mainly used as a solvent for the refining of lubricating oils and diesel fuels and as an intermediate chemical in the manufacturing of industrial solvents, such as tetrahydrofuran (THF), 2-methyltetrahydrofuran (2-MTHF), furfural alcohols, etc. Other furan derivatives that can be produced from furfural like furan, 2-methylfuran (MF) are reported as promising biofuel component. In addition, 2,5-furandicarboxylic acid (FDCA) has been identified by the US Department of Energy as one of 12 top value-added chemicals ${ }^{2-4}$.

Furfural production is based on the chemical conversion of monosaccharide (xylose). Industrial furfural production is based on the pentosan-containing lignocellulosic materials (corncob, wheat straw, rice straw, oat hulls and bagasse) hydrolysis and subsequent dehydration of the obtained pentose using mineral acids as catalyst in aqueous media. However, the mineral acids are limited for corrosion, safety problems and critical reaction conditions. Additionally, $\mathrm{H}_{3} \mathrm{PO}_{4}{ }^{5}, \mathrm{HCOOH}^{6}$ and $\mathrm{CH}_{3} \mathrm{COOH}^{7}$ used as catalyst were reported. Recently, chlorides in ionic liquid used as catalysts for furfural production is becoming a hot topic. Binder studied the production of furfural from xylose in 1-butyl-3-methylimidazolium chloride ([BMIM]Cl) using $\mathrm{CrCl}_{3}$ as a catalyst and achieved an furfural yield of $56 \%$ by holding the system at $100{ }^{\circ} \mathrm{C}$ for $4 \mathrm{~h}^{8}$. In subsequent studies, zhang reported a considerable furfural yield of $84.8 \%$ from xylan by using $\mathrm{AlCl}_{3} \cdot 6 \mathrm{H}_{2} \mathrm{O}$ in [BMIM]Cl under microwave heating at $170{ }^{\circ} \mathrm{C}$ for $10 \mathrm{~s}^{9}$. Although ideal furfural yields from xylose or xylan have been obtained, the cost of proposed system is expensive. In addition, the ionic liquid will produced passivation effect in the sugar dehydration process $^{10-12}$. Therefore, a relatively inexpensive, low-toxicity, high-speed and high-yield system is still necessary. Water has been proposed as green and ideal reaction solvent. In pure water, xylose dehydration is generally nonselective, leading to many by-products besides furfural. To overcome side reactions, the application of biphasic system (using organic solvents as extraction solvent) has recently been proposed. In this study, 
a one-pot production of furfural from xylose over $\mathrm{CrCl}_{3} \cdot 6 \mathrm{H}_{2} \mathrm{O}$ catalyst in toluene/water solvent was reported. The effects of reaction temperature, reaction time, catalyst loading and $\mathrm{NaCl}$ loading were investigated to optimize the process.

\section{EXPERIMENTAL}

D-Xylose (98\%), furfural, phloroglucinol were purchased from Aladdin. Toluene and hydrochloric acid were obtained from Huainan Chemical Reagent Co. Ltd. and glacial acetic acid, $\mathrm{NaCl}, \mathrm{CrCl}_{3} \cdot 6 \mathrm{H}_{2} \mathrm{O}, \mathrm{AlCl}_{3} \cdot 6 \mathrm{H}_{2} \mathrm{O}, \mathrm{CuCl}_{2} \cdot 2 \mathrm{H}_{2} \mathrm{O}, \mathrm{FeCl}_{3}$, $\mathrm{CoCl}_{2} \cdot 6 \mathrm{H}_{2} \mathrm{O}, \mathrm{ZnCl}_{2}$ were purchased from Sinopharm Chemical Reagent Co. Ltd. All the reagents were used as received.

Conversion of D-xylose: The conversion of D-xylose was performed in a homemade small reactor. In a typical experiment, a reactor was charged with D-xylose $(0.75 \mathrm{~g}, 5 \mathrm{mmol})$, $\mathrm{CrCl}_{3} \cdot 6 \mathrm{H}_{2} \mathrm{O}(0.533 \mathrm{~g}, 2 \mathrm{mmol}), \mathrm{NaCl}(3 \mathrm{~g})$, water $(20 \mathrm{~mL})$ and toluene $(20 \mathrm{~mL})$. Then closed and paced into the oil bath after the temperature of thermostatic oil bath rose to the reaction temperature and kept constant and zero time was taken. All solutions were mixed at the maximum constant rate using a magnetic stirrer during the reaction to prevent hot spots. The reactor was pressurized because of the vapor pressure of the solution at the reaction temperature used. At the end of the reaction, the reactor was removed from the oil bath and cooled to room temperature by flowing cold water. At last, the aqueous and organic phases were separated, diluted before the analysis.

Analytical methods: The furfural obtained from D-xylose was detected and quantified by Select Ion Method (SIM) using a DB-17column (GC-MS, QP5050A). Helium was used as carrier gas at a flow rate of $1.3 \mathrm{~mL} / \mathrm{min}$ and the initial column temperature was $80^{\circ} \mathrm{C}$ for $3 \mathrm{~min}$, followed with a ramp of 10 ${ }^{\circ} \mathrm{C} / \mathrm{min}$ to final temperature of $180^{\circ} \mathrm{C}$. The temperature of injection port and detector port were both $200^{\circ} \mathrm{C}$. Under these conditions, furfural had a retention time of $3.7 \mathrm{~min}$. The concentration of D-xylose in hydrolyzate was determined by colorimetric method $^{13}$. Firstly, weighed $5 \mathrm{~g}$ phloroglucinol reagent into a $250 \mathrm{~mL}$ Erlenmeyer flask and then added $100 \mathrm{~mL}$ glacial acetic acid and $6 \mathrm{~mL}$ hydrochloride acid. Make sure the phloroglucinol reagent completely dissolved. Secondly, pipetted the $1 \mathrm{~mL}$ diluted hydrolyzate into test tube, added 5 $\mathrm{mL}$ phloroglucinol solvent and then put them into boiling water bath for $8 \mathrm{~min}$. At last, the samples were estimated based on the absorbance at $554 \mathrm{~nm}$ using ultraviolet-visible spectrophotometer. All concentrations of D-xylose and furfural were calculated based on standard curves constructed by using authentic samples. All analyses were performed duplicate.

Calculation: The furfural yield and conversion of Dxylose were calculated by following equations:

$$
\text { Furfural yield }=\frac{\text { Moles of furfural producted }}{\text { Initial moles of xylose }} \times 100 \%
$$

Conversion of xylose $=\left(1-\frac{\text { Moles of xylose unreacted }}{\text { Initial moles of xylose }}\right) \times 100 \%$

\section{RESULTS AND DISCUSSION}

Effect of catalyst variation on the conversion of Dxylose: In preliminary experiments, D-xylose was treated with six different metal chlorides $\left(\mathrm{CrCl}_{3} \cdot 6 \mathrm{H}_{2} \mathrm{O}, \mathrm{AlCl}_{3} \cdot 6 \mathrm{H}_{2} \mathrm{O}\right.$, $\left.\mathrm{CuCl}_{2} \cdot 2 \mathrm{H}_{2} \mathrm{O}, \mathrm{FeCl}_{3}, \mathrm{CoCl}_{2} \cdot 6 \mathrm{H}_{2} \mathrm{O}, \mathrm{ZnCl}_{2}\right)$ and the results were summarized in Table-1. Compared to the absence of catalyst, all six metal chlorides could promote the conversion of Dxylose into furfural. Only $\mathrm{CrCl}_{3} \cdot 6 \mathrm{H}_{2} \mathrm{O}$ showed superior results. The yield of $38.76 \%$ was achieved within $1 \mathrm{~h}$ while the conversion of xylose was $92.07 \%$. Other catalysts, such as $\mathrm{ZnCl}_{2}$, $\mathrm{CoCl}_{2} \cdot 6 \mathrm{H}_{2} \mathrm{O}$, had no obvious catalytic activities in the conversion of xylose and gave the furfural yields less than $1 \%$. However, when $\mathrm{FeCl}_{3}, \mathrm{CuCl}_{2} \cdot 2 \mathrm{H}_{2} \mathrm{O}, \mathrm{AlCl}_{3} \cdot 6 \mathrm{H}_{2} \mathrm{O}$ were used, the furfural yield was improved to a certain degree, with final furfural yield ranging from 3.77-15.74 \% and conversion of xylose ranging from $48.36-71.57 \%$. In short, $\mathrm{CrCl}_{3} \cdot 6 \mathrm{H}_{2} \mathrm{O}$ was found to be much more effective for conversion of xylose. This result might be because that stronger Lewis acidity of $\mathrm{Cr}^{3+}$ not only lowered the barrier of the isomerization of xylose to xylulose, but also accelerated the dehydration of xylulose to furfural. Thus, the $\mathrm{CrCl}_{3} \cdot 6 \mathrm{H}_{2} \mathrm{O}$ was selected for further assessments $^{14}$.

\begin{tabular}{cccc}
\multicolumn{5}{c}{ TABLE-1 } \\
\multicolumn{4}{c}{$\begin{array}{c}\text { EFFECT OF DIFFERENT CATALYSTS ON FURFURAL } \\
\text { YIELD AND CONVERSION OF XYLOSE }\end{array}$} \\
\hline Entry & \multicolumn{1}{c}{ Catalyst } & Conversion of xylose (\%) & Furfural yield (\%) $^{\mathrm{N}}$. \\
\hline 1 & $\mathrm{No} \mathrm{catalyst}_{2}$ & 4.56 & 0.07 \\
2 & $\mathrm{CrCl}_{3} \cdot 6 \mathrm{H}_{2} \mathrm{O}$ & 92.07 & 38.76 \\
3 & $\mathrm{AlCl}_{3} \cdot 6 \mathrm{H}_{2} \mathrm{O}$ & 71.57 & 15.74 \\
4 & $\mathrm{FeCl}_{3}$ & 48.36 & 6.76 \\
5 & $\mathrm{CuCl}_{2} \cdot 2 \mathrm{H}_{2} \mathrm{O}$ & 55.35 & 3.77 \\
6 & $\mathrm{ZnCl}_{2}$ & 17.02 & 0.57 \\
7 & $\mathrm{CoCl}_{2} \cdot 6 \mathrm{H}_{2} \mathrm{O}$ & 15.02 & 0.54 \\
\hline
\end{tabular}

${ }^{a}$ Reaction conditions: $5 \mathrm{mmol}$ xylose, $2 \mathrm{mmol}$ catalyst, $20 \mathrm{~mL} \mathrm{H}_{2} \mathrm{O}, 20$ $\mathrm{mL}$ toluene, $140{ }^{\circ} \mathrm{C}, 1 \mathrm{~h}$.

Effect of reaction temperature on conversion of Dxylose: The reaction conditions were optimized by studying the effect of reaction temperature, reaction time and the catalyst loading and $\mathrm{NaCl}$ loading on $\mathrm{D}$-xylose conversion and furfural yield, the results were shown in Table-2.

Initially, the reaction temperature varied from 100 to $180{ }^{\circ} \mathrm{C}$ with other conditions remained unchanged (Table-2, entry 15). The D-xylose conversion increased from 17.7 to $99.13 \%$ with the reaction temperature increasing, but the furfural yield at the different reaction temperature was more subtle. The furfural yield increased from 1.42 to 38.76 by increasing the reaction temperature from 100 to $140{ }^{\circ} \mathrm{C}$, then decreased to 29.69 and $11.67 \%$ at the temperature of 160 and $180{ }^{\circ} \mathrm{C}$, respectively. Fig. 1 showed the furfural yields as a function of $\mathrm{D}$-xylose conversion at different reaction temperatures. It was suggested that the dehydration of D-xylose into furfural can be divided into three stages based on the reaction temperatures. In the first stage (between 100 and $120^{\circ} \mathrm{C}$ ), only a small part of D-xylose was converted into furfural, with a conversion rate of 0.28 . In the second stage (between 120 and $140{ }^{\circ} \mathrm{C}$ ), the conversion rate increased to 0.61 . In the third stage (between 140 and $180^{\circ} \mathrm{C}$ ), with D-xylose conversion further increasing, the furfural yield decreased, for side reactions (cross and polymerization) causing the loss of furfural during the higher temperature ${ }^{15}$. Our results showed that $140{ }^{\circ} \mathrm{C}$ was the best reaction temperature for the $\mathrm{CrCl}_{3} \cdot 6 \mathrm{H}_{2} \mathrm{O}$ catalyzed conversion of D-xylose to furfural in toluene/water biphasic system. 


\begin{tabular}{|c|c|c|c|c|c|}
\hline \multicolumn{6}{|c|}{$\begin{array}{c}\text { TABLE-2 } \\
\text { VARIATION OF REACTION PARAMETERS IN } \\
\text { CONVERSION OF D-XYLOSE INTO FURFURAL }\end{array}$} \\
\hline Entry & $\begin{array}{l}\text { Catalyst } \\
\text { loading } \\
(\mathrm{mmol})\end{array}$ & $\begin{array}{l}\text { Reaction } \\
\text { temp. } \\
\left({ }^{\circ} \mathrm{C}\right)\end{array}$ & $\begin{array}{l}\text { Reaction } \\
\text { time } \\
(\mathrm{min})\end{array}$ & $\begin{array}{l}\text { Conversion } \\
\text { of xylose } \\
(\%)\end{array}$ & $\begin{array}{l}\text { Furfural } \\
\text { yield } \\
(\%)\end{array}$ \\
\hline 1 & 2 & 100 & 60 & 17.70 & 1.42 \\
\hline 2 & 2 & 120 & 60 & 42.45 & 8.44 \\
\hline 3 & 2 & 140 & 60 & 92.07 & 38.76 \\
\hline 4 & 2 & 160 & 60 & 99.46 & 29.69 \\
\hline 5 & 2 & 180 & 60 & 99.13 & 11.67 \\
\hline 6 & 2 & 140 & 20 & 77.22 & 20.11 \\
\hline 7 & 2 & 140 & 40 & 88.67 & 31.06 \\
\hline 8 & 2 & 140 & 60 & 92.07 & 38.76 \\
\hline 9 & 2 & 140 & 90 & 93.87 & 35.51 \\
\hline 10 & 2 & 140 & 120 & 97.45 & 25.83 \\
\hline 11 & 1 & 140 & 60 & 90.69 & 35.87 \\
\hline 12 & 2 & 140 & 60 & 92.07 & 38.76 \\
\hline 13 & 3 & 140 & 60 & 99.57 & 38.56 \\
\hline 14 & 4 & 140 & 60 & 99.47 & 37.61 \\
\hline 15 & 5 & 140 & 60 & 99.57 & 36.34 \\
\hline
\end{tabular}

${ }^{a}$ Reaction conditions: $5 \mathrm{mmol}$ xylose, $20 \mathrm{~mL} \mathrm{H}_{2} \mathrm{O}, 20 \mathrm{~mL}$ toluene.

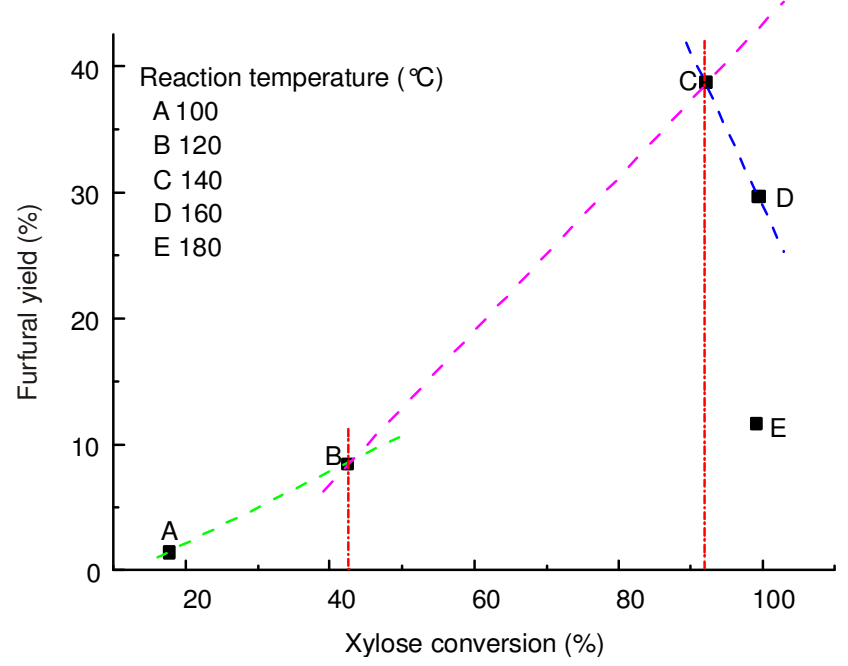

Fig. 1. Furfural yield to D-xylose conversion at different reaction temperatures

Effect of reaction time on conversion of D-xylose: The reaction time varied from 20 to $120 \mathrm{~min}$ (Table-2, entry 6-10) while the other reaction conditions were kept constant. In the first $20 \mathrm{~min}$, the D-xylose conversion and furfural yield were 77.22 and $20.11 \%$, respectively. For longer reaction time, the D-xylose conversion and furfural yield were both increased. The maximum value of furfural yield was obtained at $1 \mathrm{~h}$. After $1 \mathrm{~h}$, the furfural yield began to drop but the D-xylose conversion continued to rise slowly. Fig. 2 showed the relationship between the D-xylose conversion and furfural yield at different reaction times. The rate of conversion of D-xylose into furfural was different at different reaction times. In the first stage (0-20 $\mathrm{min})$, the rate was the lowest (0.26), while in the second stage (20-40 $\mathrm{min}$ ), the generation rate increased to 0.95 and then to 2.26 in the third stage between 40 and 60 $\mathrm{min}$. In the fourth stage (60-120 $\mathrm{min})$, the furfural yield started to decrease while the D-xylose was further increased and a linear relationship between D-xylose conversion and furfural yield was observed. It was suggested that $1 \mathrm{~h}$ was the optimum reaction time at $140{ }^{\circ} \mathrm{C}$.

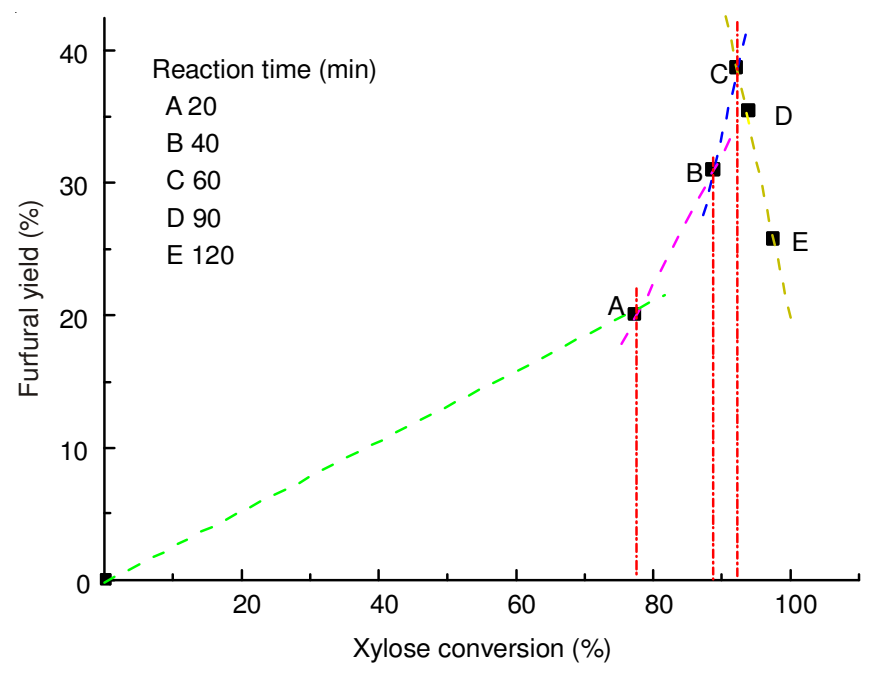

Fig. 2. Furfural yield to D-xylose conversion at different reaction times

Effect of catalyst loading on conversion of D-xylose: The effect of catalyst loading was presented in Table-2 (entry 11-15) and the relationship between furfural yield and D-xylose conversion at different catalyst loading was displayed in Fig. 3. The results indicated that $\mathrm{D}$-xylose conversion and furfural yield significantly increased when the catalyst was less than 2 mmol, the furfural yield achieved the maximum value of $38.76 \%$ at the catalyst loading of 2 mmol. However, as the catalyst loading beyond the $2 \mathrm{mmol}$, the furfural yield gradually decreased for side reactions converting furfural to humin ${ }^{16}$. The optimal catalyst loading was $2 \mathrm{mmol}$.

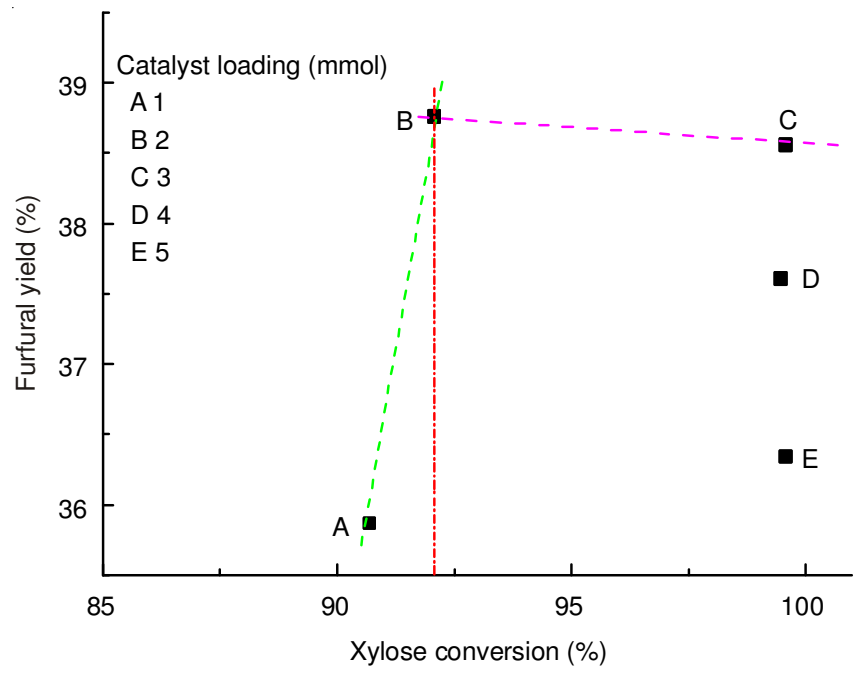

Fig. 3. Furfural yield plotted as a function of D-xylose conversion at different catalyst loading

Effect of $\mathrm{NaCl}$ loading on conversion of D-xylose: The effect of salt has been suggested to enhance the partition coefficient of furfural in organic phase ${ }^{17}$. Further studies were done to optimize the efficiency. Different amounts of $\mathrm{NaCl}$ were added to the aqueous phase (Table-3). The results showed that the furfural yield achieved to $52.55 \%$ with $3 \mathrm{~g} \mathrm{NaCl}$ for $1 \mathrm{~h}$ at $140{ }^{\circ} \mathrm{C}$. Compared to the absence of $\mathrm{NaCl}$, the furfural yield increased $35.58 \%$. However, a further increasing in the $\mathrm{NaCl}$ loading did not result in better furfural yield, presumably due to furfural dehydration. Finally, the catalytic stability of 


\begin{tabular}{cccc}
\hline \multicolumn{5}{c}{ TABLE-3 } \\
\multicolumn{5}{c}{$\begin{array}{c}\text { EFFECT OF NaCl LOADING ON FURFURAL } \\
\text { YIELD AND CONVRSION OF XYLOSE }\end{array}$} \\
\hline \multirow{2}{*}{ Entry } & $\begin{array}{c}\text { NaCl loading } \\
(\mathrm{g})\end{array}$ & $\begin{array}{c}\text { Conversion of } \\
\text { xylose }(\%)\end{array}$ & $\begin{array}{c}\text { Furfural yiled }^{(\%)} \\
\end{array}$ \\
\hline 1 & 0 & 92.07 & 38.76 \\
2 & 1 & 95.57 & 44.43 \\
3 & 2 & 98.48 & 47.61 \\
4 & 3 & 98.66 & 52.55 \\
5 & 4 & 97.16 & 50.52 \\
6 & 5 & 94.95 & 48.55 \\
$7^{\mathrm{b}}$ & 3 & 98.57 & 52.88 \\
$8^{\mathrm{c}}$ & 3 & 97.98 & 51.52 \\
\hline
\end{tabular}

${ }^{a}$ Reaction condition: $5 \mathrm{mmol}$ xylose, $2 \mathrm{mmol} \mathrm{CrCl}_{3} \cdot 6 \mathrm{H}_{2} \mathrm{O}, 20 \mathrm{~mL} \mathrm{H} \mathrm{H}_{2} \mathrm{O}$, $20 \mathrm{~mL}$ toluene, $140{ }^{\circ} \mathrm{C}, 1 \mathrm{~h}$. ${ }^{b}$ Entry 7 used recycled $\mathrm{CrCl}_{3} \cdot 6 \mathrm{H}_{2} \mathrm{O}-\mathrm{NaCl}$ catalytic system after the fresh catalyst system has been used one time. ${ }^{c}$ Entry 8 used recycled $\mathrm{CrCl}_{3} \cdot 6 \mathrm{H}_{2} \mathrm{O}-\mathrm{NaCl}$ catalytic system after the fresh catalyst system has been used two times.

$\mathrm{CrCl}_{3} \cdot 6 \mathrm{H}_{2} \mathrm{O}-\mathrm{NaCl}$ catalyst system in the biphasic system were investigated (Table-3, entry 7-8). The results showed that the furfural yield in toluene reached a steady value for reusing two times without reducing the catalytic activity of catalyst. So the $\mathrm{NaCl}$ can be used as co-catalyst to increase the furfural selection.

Conversion of corncob into furfural: Novel catalytic system developed for biomass-processing must always be assessed with real samples. Therefore, the $\mathrm{CrCl}_{3} \cdot 6 \mathrm{H}_{2} \mathrm{O}-\mathrm{NaCl}$ catalytic system was also tested for catalyzing conversion of corncob into furfural. In Table-4, furfural yield was $14.31 \%$ at $140{ }^{\circ} \mathrm{C}$ for $1 \mathrm{~h}$ when the $\mathrm{CrCl}_{3} \cdot 6 \mathrm{H}_{2} \mathrm{O}$ was separately used as a catalyst, while $\mathrm{NaCl}$ was used as co-catalyst, good result was observed. The furfural yield of $23.88 \%$ was obtained. These results demonstrated that the $\mathrm{CrCl}_{3} \cdot 6 \mathrm{H}_{2} \mathrm{O}-\mathrm{NaCl}$ catalytic system was suitable for the conversion of lignocellulose into furfural.

\begin{tabular}{ccc}
\multicolumn{4}{c}{ TABLE-4 } \\
\multicolumn{3}{c}{ CONVERSION OF CORNCOB INTO FURFURAL } \\
WITH CrCl $6 \mathrm{H}_{2} \mathrm{O}-\mathrm{NaCl}$ CATALYTIC SYSTEM \\
\hline Entry & Catalyst & Furfural yield (\%) \\
\hline 1 & $\mathrm{CrCl}_{3} \cdot 6 \mathrm{H}_{2} \mathrm{O}$ & 14.31 \\
2 & $\mathrm{CrCl}_{3} \cdot 6 \mathrm{H}_{2} \mathrm{O}-\mathrm{NaCl}$ & 23.88 \\
\hline${ }^{2}$ Reaction condition: $2 \mathrm{~g} \mathrm{corncob}_{2} 2 \mathrm{mmol} \mathrm{CrCl} \cdot 6 \mathrm{H}_{2} \mathrm{O}, 3 \mathrm{~g} \mathrm{NaCl}, 20$ \\
$\mathrm{~mL} \mathrm{H}_{2} \mathrm{O}, 20 \mathrm{~mL}$ toluene, $140{ }^{\circ} \mathrm{C}, 1 \mathrm{~h}$.
\end{tabular}

\section{Conclusion}

In this study, a new catalytic system based on the catalyst $\mathrm{CrCl}_{3} \cdot 6 \mathrm{H}_{2} \mathrm{O}$ with $\mathrm{NaCl}$ as co-catalyst has been established for the efficient conversion of D-xylose into furfural. An excellent furfural yield of $52.55 \%$ was achieved in following conditions: reaction temperature $140{ }^{\circ} \mathrm{C}$, reaction time $1 \mathrm{~h}$, catalyst loading $2 \mathrm{mmol}, \mathrm{NaCl}$ loading $3 \mathrm{~g}$, toluene $20 \mathrm{~mL}$ and water $20 \mathrm{~mL}$. The catalytic system could reuse without significant activity loss. In addition, when corncob was used as start materials, a furfural yield of $23.88 \%$ was also obtained.

\section{ACKNOWLEDGEMENTS}

This research was carried out with support of the National Natural Science Foundation of China (Grant No. 21376007), the National Key Technology R\&D Program of China (Grant No. 2014BAD02B03), the Key Project of Fund of Education Department of Anhui Province(KJ2012A084) and the Colleges Natural Science Foundation of Anhui Educational Committee of China (Grant No. KJ2013Z074).

\section{REFERENCES}

1. Z.Z. Chen, Q. Chen, J.L. Yang, et al., Trans. Chinese Soc. Agric. Eng., 28, 214 (2012).

2. P. Gallezot, Chem. Soc. Rev., 41, 1538 (2012).

3. M.X. Gao, Z.Z. Liu and M.H. Zhang, Chem. Ind. Eng. Prog., 32, 878 (2013).

4. X.M. Yu, L.J. Yu, Y.W. Gong, et al., Chem. Eng., 7, 13 (2009).

5. D.S. Xiang, X. Zhu and T. Zeng, Modern Chem. Ind., 30, 63 (2010).

6. K. Lamminpaa, J. Ahola and J. Tanskanen, Ind. Eng. Chem. Res., 51, 6297 (2012).

7. L.Y. Mao, L. Zhang, N.B. Gao and A. Li, Bioresour. Technol., 123, 324 (2012).

8. J.B. Binder, J.J. Blank, A.V. Cefali and R.T. Raines, ChemSusChem, 3, 1268 (2010)

9. L.X. Zhang, H.B. Yu, P. Wang, H. Dong and X. Peng, Bioresour. Technol., 130, 110 (2013).

10. L. Hu, Y. Sun and L. Lu, Process Chem., 24, 483 (2012).

11. T. Vom Stein, P.M. Grande, W. Leitner and P. Domínguez de María, ChemSusChem, 4, 1592 (2011).

12. Y. Yang, C.W. Hu and M.M. Abu-Omar, ChemSusChem, 5, 405 (2012).

13. T.J. Eberts, R.H. Sample, M.R. Glick and G.H. Ellis, Clin. Chem., 25, 1440 (1979).

14. L. Hu, Y. Sun and L. Lin, Ind. Eng. Chem. Res., 51, 1099 (2012).

15. C.B. Lu, CIESC J., 60, 3035 (2009).

16. V. Choudhary, S.I. Sandler and D.G. Vlachos, ACS Catal., 2, 2022 (2012).

17. Y. Roman-Leshkov, C.J. Barrett, Z.Y. Liu and J.A. Dumesic, Nature, 447, 982 (2007). 